\title{
Low glutathione reductase and peroxidase activity in age-related macular degeneration
}

Steven M Cohen, Katherine L Olin, William J Feuer, Leonard Hjelmeland, Carl L Keen, Lawrence S Morse

\begin{abstract}
Age-related macular degeneration (ARMD) may result from events initiated by reactive oxygen species. Blood samples from 18 patients with ARMD and 18 similarly aged controls were analysed for activities of important antioxidants. Blood glutathione reductase activity was lower in patients with ARMD compared with controls $(p=0.035)$. The activities of glutathione peroxidase $(p=0 \cdot 18)$ and erythrocyte superoxide dismutase $(p=0.29)$ were similar between the two groups by a Student's two sample $t$ test. Logistic regression was used to determine which enzyme activities were associated with ARMD after adjusting for possible confounding variables: smoking history, age, multivitamin use, and cardiovascular disease. Glutathione reductase activity $(p=0.05)$ and glutathione peroxidase activity $(p=0.065)$ were significantly associated with ARMD by this analysis. The relation of glutathione reductase and glutathione peroxidase activity to ARMD merits further study. (Brf Ophthalmol 1994; 78: 791-794)
\end{abstract}

Age-related macular degeneration (ARMD) is a leading cause of irreversible vision loss in the United States, United Kingdom, and other developed nations. ${ }^{1-6}$ This disease affects $20-30 \%$ of people over the age of $75 .{ }^{17}$ Since this section of the population is expected to increase dramatically during the next century, ARMD is a public health problem of severe and growing proportions. ${ }^{8}$ Although some risk factors for ARMD have been identified, its cause remains unknown. ${ }^{19-12}$ An improved understanding of the aetiology and pathogenesis of ARMD at the cellular and biochemical level is crucial to developing improved treatment and hopefully even prevention of this disease.

It has been suggested that ARMD may result in part from a cascade of events initiated by reactive oxygen species. ${ }^{71314}$ These reactive oxygen species may damage lipids in the outer segments of photoreceptors and lead to progressive deterioration of the retinal pigment epithelium (RPE). ${ }^{915}$ Others propose that circulating reactive oxygen species could damage the choriocapillaris and lead to ARMD. ${ }^{13}$ Deficiencies of select trace elements, such as zinc, have also been implicated in the vision loss caused by ARMD. ${ }^{16-18}$

Accordingly, we report the results of a casecontrol study of patients with ARMD aimed at detecting possible alterations in enzyme activities which have critical roles in cellular defence against reactive oxygen species

\section{Patients and methods}

All patients examined in the UC Davis Department of Ophthalmology by the authors (LM and SC) from September 1989 through September 1992 were considered for this study. Thirty six subjects were entered into the study based on the criteria listed below. This study was approved by the UC Davis, human subjects committee. Subjects with diabetes, a major systemic disease, or a visually compromising eye disease were excluded from the study. Patients with visually significant cataracts were also excluded along with all individuals taking zinc supplements or high dose vitamin supplements. However, subjects taking a multivitamin supplement were not excluded. These multivitamin supplements contained $100 \%$ to $200 \%$ of the recommended daily dietary allowances of vitamin A (5000 IU), vitamin C (60 mg), and vitamin E (30 IU). ${ }^{19}$

Patients included in the ARMD group had a Snellen visual acuity of $20 / 40$ or worse and had to have at least 10 ophthalmoscopically visible macular drusen, characteristic pigmentary geographic atrophy, and/or subretinal neovascular membranes. Subjects whose visual loss may have been secondary to a media opacity were excluded.

The control group consisted of subjects who had fewer than two ophthalmoscopically visible macular drusen in each eye and an associated Snellen visual acuity of 20/30 or better in both eyes. Most of these patients presented to the clinic with refractive problems.

Participants in the study were asked a standard series of questions. This patient history questionnaire focused on previously identified risk factors for ARMD. ${ }^{9}$ Each subject had visual acuity testing with best correction, slit-lamp examination noting any media opacities, and applanation tonometry. The fundus was examined in all subjects using either contact or non-contact lens biomicroscopy. Fundus photographs were taken in most patients and fluorescein angiography was done only when clinically indicated.

At the time of examination, venous blood was drawn into a heparinised tube free from trace element contamination. Those that processed the blood and performed the assays were masked to the subjects' diagnoses. Aliquots of whole blood were stored at $-70^{\circ} \mathrm{C}$ for subsèquent analysis of glutathione peroxidase and glutathione reductase activities. The remaining blood was centrifuged at $1700 \mathrm{~g}$ for 20 minutes, and plasma fractions were stored at $-70^{\circ} \mathrm{C}$. Réd cell lysates were prepared by diluting packed red blood cells with an equal volume of distilled, deionised water, mixing and centrifuging at $1700 \mathrm{~g}$; the supernates were stored at $-70^{\circ} \mathrm{C}$ until used for 
determining erythrocyte superoxide dismutase activity.

Analytical grade chemicals and reagents were purchased from Sigma Chemical Co (St Louis, MO, USA) unless otherwise noted. Blood glutathione peroxidase activity was measured according to the methods of Lawrence and Burk ${ }^{20}$ ) and Agergaard and Jensen. ${ }^{21}$ Selenium dependent glutathione peroxidase activity was measured by using $5 \mathrm{mM}$ hydrogen peroxide in the assay system. Blood glutathione reductase activity was measured as described by Rogers and Augusteyn. ${ }^{22}$ Following the extraction of haemoglobin from the red cell lysates, superoxide dismutase activity was determined according to Marklund and Marklund. ${ }^{23}$ Haemoglobin concentrations were determined by the cyanomethaemoglobin colorimetric procedure (Sigma Diagnostic Kit No 525).

Results are presented as the mean (SEM). p Values were computed with Student's two sample $t$ test. Backward stepwise multiple logistic regression was used to determine what variables were significantly related to the subjects' disease status. Variables were removed from models if their maximum likely $\mathrm{p}$ values were greater than or equal to $0 \cdot 1$. $p$ Values were calculated with maximum likelihood methods while confidence intervals were obtained from asymptotic standard errors. Enzyme activities were fitted as continuous variables.

Table 1 Historical profile of patients with age-related macular degeneration (ARMD) and controls

\begin{tabular}{lcc}
\hline & $A R M D$ & Control \\
& No(\%) & No(\%) \\
\hline Total patients & 18 & 18 \\
Average age (range) & $74(60-96)$ & $76(68-87)$ \\
Ever smoked & $11(61)$ & $9(50)$ \\
Currently smokes & $4(22)$ & $2(11)$ \\
Stroke & $4(22)$ & $2(11)$ \\
Hypertension & $10(59)$ & $8(44)$ \\
Angina & $6(35)$ & $2(11)$ \\
Myocardial infarct & $6(35)$ & $0(0)$ \\
Multivitamin (currently) & $3(17)$ & $7(39)$ \\
Family history of ARMD & $3(17)$ & $1(6)$ \\
Female & $11(61)$ & $8(44)$ \\
White & $18(100)$ & $18(100)$ \\
\hline
\end{tabular}

Table 2 Examination profile of patients with age-related macular degeneration (ARMD) and controls

\begin{tabular}{lcc}
\hline & ARMD & Control \\
\hline Visual acuity, right eye & $20 / 80$ & $20 / 20$ \\
Visual acuity, left eye & $20 / 200$ & $20 / 20$ \\
Visual acuity, worse eye & $20 / 300$ & $20 / 20$ \\
Visual acuity, better eye & $20 / 60$ & $20 / 20$ \\
Intraocular pressure, right eye $(\mathrm{mm} \mathrm{Hg}) \dagger$ & $15(0 \cdot 9)$ & $16(0 \cdot 6)$ \\
Intraocular pressure, left eye (mm Hg)† & $16(0 \cdot 9)$ & $15(0 \cdot 6)$ \\
Systolic blood pressure (mm Hg) $\dagger$ & $140(5)$ & $134(4)$ \\
Diastolic blood pressure (mm Hg) $\dagger$ & $77(2)$ & $75(2)$ \\
Pseudophakiał & $5(28)$ & $2(11)$ \\
Blue irisł & $7(39)$ & $11(61)$ \\
\hline
\end{tabular}

* Values are expressed as geometric mean of standard Snellen units.

tValues are expressed as mean (SEM).

$¥$ No $(\%)$.

Fable 3 Blood antioxidant enzyme activities

\begin{tabular}{|c|c|c|c|}
\hline & $A R M D$ & Control & $p$ Value \\
\hline \multirow{3}{*}{$\begin{array}{l}\text { Erythrocyte superoxide dismutase (units mg } \mathrm{Hb}^{-1} \text { ) } \\
\text { Blood glutathione reductase (nmol NADPH oxidised } \\
\text { min }^{-1} \text { mg Hb } \\
\text { Blood glutathione peroxidase (nmol NADPH oxidised } \\
\text { min }^{-1} \text { mg Hb } \\
\text { (n) }\end{array}$} & $0.930(0.04)$ & $0.884(0.02)$ & $0 \cdot 29$ \\
\hline & $3.81 \quad(0.39)$ & $5.09 \quad(0.43)$ & 0.035 \\
\hline & $(0 \cdot 72)$ & $(0 \cdot 54)$ & $0 \cdot 18$ \\
\hline
\end{tabular}

Values are expressed as mean (SEM)

p Values are from two sample Student's $t$ test.

\section{Results}

Historical profiles of ARMD and control subjects are presented in Table 1 . The mean age of the control group was 74 years, ranging from 60 to 96; the mean age of the ARMD group was 76 years, ranging from 68 to 87 .

Results from the clinical examination are presented in Table 2. Subjects in the ARMD group had poor visual acuity with a geometric mean Snellen visual acuity of 20/80 right eye, 20/200 left eye. In contrast, the control group had excellent visual acuity with a geometric mean Snellen visual acuity of $20 / 20$ in both eyes. Comparing right eyes, left eyes, better eyes, or worse eyes geometric mean visual acuity was significantly poorer in the ARMD group than in controls $(p<0.001)$. There was no difference in degree of lens opacity between the ARMD group and controls. Five (28\%) ARMD patients compared with two (11\%) controls were bilaterally pseudophakic.

Results of antioxidant enzyme activities are presented in Table 3. Glutathione reductase activity was significantly lower in ARMD subjects compared with controls $(p=0.035)$. The activities of glutathione peroxidase and erythrocyte superoxide dismutase were similar between the two groups.

Logistic regression was used to determine which of the antioxidant enzyme activities were associated with disease status after adjusting for possible confounding variables: smoking history, age, multivitamin use, and cardiovascular factors including stroke, hypertension, angina, myocardial infarction. All six patients with myocardial infarction were in the ARMD group (significant by two tailed Fisher's exact test, $\mathrm{p}=0.019$ ) so these cases were excluded from the logistic regression analysis. The only variables which were found to be significantly related to disease status by logistic regression analysis were glutathione reductase activity $(p=0.05)$ and glutathione peroxidase activity $(p=0.065)$. The odds ratios associating decreased enzyme activities with ARMD were 1.63 (95\% confidence interval $=1.0$ to 2.8 ) for glutathione reductase and $1.36(95 \%$ confidence interval $=1.0$ to 2.0$)$ for glutathione peroxidase.

\section{Discussion}

Given that the prevalence of ARMD is strongly correlated with age, it is reasonable to speculate that the deterioration of the neurosensory macula, the RPE, and the choriocapillaris in ARMD may be secondary to mechanisms associated with the aging process. While the process of aging is poorly understood, several theories have been proposed to help explain events leading to decrease viability and eventually death in a seemingly time programmed manner. One of the leading theories of aging links damage caused by reactive oxygen species to several known aging processes. ${ }^{24}$ Reactive oxygen species are molecules which contain an unpaired electron making them highly reactive. This high reactivity leads to toxic effects on more stable molecules. Reactive oxygen species are produced in all tissues during aerobic metabolism and they can also be formed by photochemical reactions. ${ }^{15}{ }^{25}$ Since the 
retina is metabolically very active, exposed to high oxygen concentrations, and exposed to focused light energy, it is subject to high concentrations of reactive oxygen species. Some of the toxic effects that these reactive molecules have no healthy surrounding tissues are a decline in cellular function caused by reduced enzyme activities, increased error rates in nucleic acid metabolism, damaged membranes, and accumulation of undigestible deformed cellular material in lysosomes. ${ }^{25}$

In the eye, antioxidant damage is correlated with senile cataract and exudative macular degeneration. ${ }^{26}{ }^{27} \mathrm{We}$ did not include any patient in this study with a visually significant cataract. The higher incidence of pseudophakia in the ARMD group (28\%) compared with controls (11\%), however, may imply that ARMD subjects developed more visually significant cataracts than controls. Although several large epidemiological studies have investigated the relation between senile cataract and ARMD, their association remains controversial..$^{-12} 14$

The body has several defences against damage induced by reactive oxygen species. In this study, we focused our attention on three enzymes, erythrocyte superoxide dismutase, glutathione reductase, and glutathione peroxidase, which serve key functions in the elimination of reactive oxygen species. We found no difference in activity of erythrocyte superoxide dismutase in ARMD subjects versus controls. We did, however, find significantly low blood glutathione reductase activities in ARMD patients compared with controls. In addition, a multiple logistic regression analysis showed that ARMD patients were more likely to have lower levels of both glutathione reductase and glutathione peroxidase.

Glutathione peroxidase can reduce hydrogen peroxide and a variety of organic peroxides using glutathione as an electron donor. ${ }^{24}$ Therefore, low glutathione peroxidase activity may render patients with ARMD susceptible to damage from reactive oxygen species. Glutathione peroxidase activity is dependent on selenium. Interestingly, a recent case control study found a borderline association between ARMD and low serum selenium concentrations; however, no such association was found in the Eye Disease CaseControl Study report. ${ }^{27}$

Recently, a decreased glutathione reductase activity in lens epithelial cells was shown to be associated with senile cataract. ${ }^{29}$ Although glutathione reductase is not directly an antioxidant, its proper function is essential to the maintenance of available reduced glutathione, a potent scavenger of reactive oxygen species. Following its reaction with a reactive oxygen species, glutathione is oxidised and subsequently returned to its reduced state by glutathione reductase ${ }^{24}$ Low glutathione reductase activity can occur for at least two reasons. Firstly, genetic variants of the enzyme exist with variable activity. These variations have been quantified in several populations and range in prevalence from $0.3 \%$ to $22 \%$. ${ }^{30}$ Secondly, riboflavin deficient individuals are characterised by lower than normal glutathione reductase activity. ${ }^{31}$

The Eye Disease Case-Control Study pre- sented evidence that antioxidant blood levels may be associated with a decreased risk of developing neovascular ARMD. ${ }^{27}$ Similarly, our data would suggest that individuals with low glutathione reductase activity and glutathione peroxidase activity are at increased risk of developing ARMD. Despite current evidence that decreased activity of blood antioxidant enzyme activity is associated with ARMD, it is premature to recommend the use of antioxidant vitamin supplements for patients with ARMD. The AgeRelated Eye Disease Study is conducting a long term randomised clinical trial to evaluate the effect of vitamin and mineral supplements on the development of ARMD.

Supported in part by a grant in aid from Fight for Sight, Inc, Research Division of the National Society to Prevent Blindness and NIH grant DK 35747 .

1 Framingham Eye Study. Macular degeneration. Surv Ophthalmol 1980; 24 (Suppl): 428-57.

2 Ghafour IM, Allan D, Foulds WS. Common causes of blindness and visual handicap in the west of Scotland. $B r f$ Ophthalmol 1983; 67: 209-13.

3 Grey RH, Burns-Cox CJ, Hughes A. Blind and partial sight registration in Avon. Brf Ophthalmol 1989; 73: 88-94.

4 MacDonald AE. Causes of blindness in Canada. Can Med Assoc 7 1965; 92: 264-79.

5 Rosenberg T. Prevalence of blindness caused by senile macular degeneration in Greenland. Arctic Med Res 1987; 46: 64-70.

6 Thompson JR, Du L, Rosenthal AR. Recent trends in the registration of blindness and partial sight in Leicestershire BrF Ophthalmol 1989; 73: 95-9.

7 Young RW. Pathophysiology of age-related macular degeneration. Surv Ophthalmol 1987; 31: 291-306.

8 Johnson ML. Aging of the United States population. Der matologic Clinics 1986; 4: 371-7.

9 Goldberg J, Flowerdew G, Smith E, Brody JA, Tso MO. Factors associated with age-related macular degeneration. An analysis of data from the first National Health and Nutrition Examination Survey. Am $\mathcal{F}$ Epidemiol 1988; 128: 700-10.

10 Ferris FL. Senile macular degeneration: review of epidemiologic features. Am 7 Epidemiol 1983; 118: 132-51.

11 Hyman LG, Lilienfield AM, Ferris FL, Fine SL. Senile macular degeneration: a case-control study. Am $\mathcal{F}$ Epidemiol 1983; 118: 213-27.

12 West SK, Rosenthal FS, Bressler NM, Bressler SB, Munoz B, Fine SL, et al. Exposure to sunlight and other risk factors for age-related macular degeneration. Arch Ophthalmol 1989 107: 875-9.

13 Gottsch JD, Pou S, Bynoe LA, Rosen GM. Hematogenous photosensitization: a mechanism for the development of agerelated macular degeneration. Invest Ophthalmol Vis Sci 1990; 31: 1674-82.

14 Taylor HR. Ultraviolet radiation and the eye: an epidemiologic study. Trans Am Ophthalmol Soc 1989; 98: 802-53.

15 Young RW. Solar radiation and age-related macular degeneration. Surv Ophthalmol 1988; 32: 252-69.

16 Newsome DA, Swartz M, Leone NC, Elston RC, Miller E. Oral zinc in macular degeneration. Arch Ophthalmol 1988 106: 192-8.

17 Weiter JJ. Macular degeneration: is there a nutritional component? Arch Ophthalmol 1988; 106: 183-4.

18 Silverstone BZ, Landau L, Berson D, Sternbuch J. Zinc and copper metabolism in patients with senile macular degeneration. Ann Ophthalmol 1985; 17: 419-22.

19 National Academy of Sciences. Recommended Daily Dietary Allowances: designed for the maintenance of good nutrition of practically all healthy people in the United States. 1989 recommendations of the Food and Nutrition Board National Academy of Sciences, Washington DC.

20 Lawrence RA, Burk RF. Glutathione peroxidase activity in selenium-deficient rat liver. Biochem Biophys Res Commun 1976; 71: 952-8.

21 Agergaard N, Jensen PT. Procedure for blood glutathione peroxidase determination in cattle and swine. Acta Vet Scand 1982; 23: 515-27.

22 Rogers KM, Augusteyn RC. Glutathione reductase in norma and cataractous human lenses. Exp Eye Res 1978; 27: 719 21 .

23 Marklund S, Marklund G. Involvement of the superoxide anion radical in the autoxidation of pyrogallol and a convenient assay for superoxide dismutase. Eurf Biochem 1974; 47: 469-74.

24 Balin AK, Allen RG. Mechanisms of biologic aging. Dermatologic Clinics 1986; 4: 347-58.

25 Leibovitz BE, Siegel BV. Aspects of free radical reactions in biological systems: aging. $\mathcal{F}$ Gerontol 1980; 35: 45-56.

26 Leske MC, Chylack LT, Wu SY, The Lens Opacities CaseControl Study Group. The lens opacities case-control study: risk factors for cataract. Arch Ophthalmol 1991; 109: 244-51.

27 Eye Disease Case-Control Study Group. Antioxidant status and neovascular eye-related macular degeneration. Arch Ophthalmol 1993; 111: 104-9. 
28 Tsang NCK, Penfold PL, Snitch PJ, Billson F. Serum levels of antioxidants and age-related macular degeneration. Doc Ophthalmol 1992; 81: 387-400.

29 Straatsma BR, Lightfoot DO, Barke RM, Horwitz J. Lens capsule and epithelium in age-related cataract. $A m \mathcal{F} O p h-$ thalmol 1991; 112: 283-96.
30 El-Hazmi MA, Warsy AS. Glutathione reductase in the southwestern province of Saudi Arabia - genetic variation vs. acquired deficiency. Haematologica 1989; 22: 37-42.

31 Bates CJ. Human riboflavin requirements and metabolic consequences of deficiency in man and animals. World Rev Nutr Diet 1987; 50: 215-65.
Around the 1880s, eminent British ophthalmologists became concerned with matters which they sincerely believed would save hundreds of lives. This was no technical innovation, but merely the institution of proper sight testing for those who piloted boats, trains, and planes. At that time, the official requirements were lax ships required only a 'percentage of seamen' to have 'approximately normal' vision and officialdom seemed completely oblivious of the dangers of defective sight.

Ophthalmologists thus felt duty bound to instruct the government and regulatory bodies, and those arriving by horsedrawn cab for the meeting of the Ophthalmic Society on 9 March 1882 would have been party to the following debate: W A Brailey, dressed in the customary top hat and frock coat, opened with the statement that the 'Tests of vision at sea' drawn up by the International Medical Congress in 1881 were somewhat inadequate, yet had been opposed on the grounds that 'defects of vision have no practical interest'. Presumably, murmurs of dissent were heard in the gas-lit room.

To refute this, Dr Fitzgerald recounted a case whereby a seaman was promoted to captain and on his maiden voyage ran into and sank another vessel while coming into port. He was reprimanded and demoted for 6 months, then reinstated. Steering into port on his second voyage he ran down a steamer lying at anchor, and at the subsequent tribunal, he was dismissed in disgrace and obtained a post on a smaller vessel. By interviewing the man and his colleagues, Fitzgerald ascertained that his vision was so impaired that he had 'long been unable to recognise street names and the numbers on omnibuses'.

It was agreed that testing of both colour and acuity should be done, preferably by someone medically qualified, on all sailors involved in signalling and lookout. Although it was noted that a member of parliament had promised to raise the matter in the House during the current session, feelings were still running high 3 years later at the meeting of January 1895. Then, $\mathrm{Mr}$ Bickerstaff reported the case of the Iron Duke which, sailing in convoy, altered its course to avoid a ship seen ahead by one of the five watchmen. This caused it to collide with the Vanguard, and a quarter of a million pounds' worth of equipment sank to the bottom. During the inquiry, the First Sea Lord heard with fury that the only lookout man to see this 'phantom ship' had defective vision, having twice been treated for blindness. Parliament rose up in wrath at this, as did the ophthalmologists who sent an urgent deputation, via the British Medical Association, to the Board of Trade.

Seventy years later, in 1953, the great increase in commercial air travel led the next generation of eminent ophthalmologists to consider the question of pilots' vision, the Civil Aeronautics Administration having announced (unsurprisingly) that candidates with normal vision were more likely to succeed at flight training. However, it was concluded that candidates with defective vision managed quite well if they lived to become suitably experienced. Therefore, the CAA decided to accept future trainees with defective vision, providing that their performance on landing was scrutinised before awarding them a licence! The ophthalmologists had no quarrel with this, but considered that possibly central and peripheral vision should be tested separately, as diseases such as retinitis pigmentosa could affect the latter only. (It was commented that this affliction made approach shots at golf rather difficult.) However, one ophthalmologist knew an Imperial Airways pilot with retinitis pigmentosa who asserted that the worst moments of his day were crossing Victoria station in the mornings and evenings. The company concluded that high visual acuity may not, in fact, be paramount in flying. (NB For those who feel worried, the CAA now insists on $6 / 9,6 / 9$ with satisfactory colour and peripheral vision.)

With regard to trains, the Snellen test was employed to yield a standard of vision allowing a driver to see the rails up to the next curve, and for those who drove electric trains in a closed cabin, spectacles could be worn. This was felt to be satisfactory. With visual standard for motor drivers, mortality statistics (15 fatalities a day) raised cries of 'something must be done', until it was stated that more accidents occurred in the home. 'To be logical, therefore, we should not stay at home, but should seek the relative safety of our motor cars,' stated the President, and having apparently exhausted their ire on ships and planes, the company turned to other matters.

F ROMAN

Brailey WA. Tests of vision at sea. Trans Ophthalmol Soc UK 1882 2: 184-97.

Mackay G. Eyesight and the public services. Trans Ophthalmol So UK 1895; 15: 199-205.

Visual requirements in relation to modern travel. Trans Ophthalmol Soc UK 1953; 73: 334-45. 